\title{
Prognóstico do acidente vascular cerebral em paciente com SARS-CoV- 2 e cirurgia de revascularização do miocárdio
}

\author{
Prognosis of stroke in a patient with SARS-CoV-2 and coronary artery bypass graft \\ surgery
}

\begin{abstract}
Pronóstico del accidente cerebrovascular en un paciente con SARS-CoV-2 y cirugía de injerto de derivación de arteria coronaria
\end{abstract}

Felipe Gustavo Morais Menegassi ${ }^{1 *}$, Valéria Cardoso Pinto Resende ${ }^{2,3}$, Flávio José Dutra de Moura ${ }^{3}$.

\section{RESUMO}

Objetivo: Relatar um caso de um paciente com acidente vascular cerebral isquêmico, cirurgia de revascularização do miocárdio (CRVM) prévia, comorbidades cardiovasculares e endócrino-metabólicas associados a complicações pelo SARS-CoV-2. Detalhamento do caso: Paciente com 75 anos, admitido em hospital de referência em Brasília/DF em junho de 2020 por perda súbita de consciência, hemiparesia em dimídio direito e afasia com desvio conjugado ocular por 1 hora. Apresentava doença arterial coronariana e cirurgia de revascularização do miocárdio há 3 anos, hipertensão arterial, doença renal crônica estágio IV pelo Chronic Kidney Disease Epidemiology Collaboration, hipotireoidismo, síndrome metabólica e síndrome da apneia obstrutiva do sono. Durante internação foi realizado o RT-PCR com detecção do RNA do SARSCoV-2 e TC de tórax demonstrando opacidades com atenuação em padrão vidro fosco e broncopatia inflamatória. Considerações finais: Na presença de coronavírus, o AVC isquêmico surge nos casos mais graves da doença, devido ao neurotropismo do vírus e às complicações do paciente com comorbidades cardiovasculares. A cirurgia de revascularização do miocárdio representa fator de pior prognóstico quando em pós-operatório imediato nesses pacientes, devido à alta taxa de letalidade. Contudo no caso em tela, o paciente com passado de CRVM teve desfecho clínico favorável.

Palavras-chave: SARS-CoV-2, Acidente vascular cerebral, Revascularização miocárdica.

\section{ABSTRACT}

Objective: To report a case of a patient with ischemic stroke, previous coronary artery bypass graft surgery (CABG), cardiovascular and endocrine-metabolic comorbidities associated with complications from SARSCoV-2. Case details: A 75-year-old patient admitted to a referral hospital in Brasilia/Federal District in June 2020 due to sudden loss of consciousness, hemiparesis in right dimidium and aphasia with conjugated ocular deviation for 1 hour. He has coronary artery disease with coronary artery bypass graft surgery 3 years ago, arterial hypertension, chronic kidney disease stage IV by the Chronic Kidney Disease Epidemiology Collaboration, hypothyroidism, metabolic syndrome and obstructive sleep apnea syndrome. During hospitalization, RT-PCR was performed with detection of the RNA of SARS-CoV-2 and chest CT showing opacities with ground-glass attenuation and inflammatory bronchopathy. Final considerations: In the presence of coronavirus, ischemic stroke occurs in the most severe cases of the disease, due to the neurotropism of the virus and the complications of the patient with cardiovascular comorbidities. Coronary artery bypass graft surgery represents a worse prognosis factor when in the immediate postoperative period in these patients with a high mortality rate. However, in the present case, the patient with a history of CABG had a favorable clinical outcome.

Key words: SARS-CoV-2, Stroke, Myocardial revascularization.

${ }^{1}$ Centro Universitário do Planalto Central (Uniceplac), Brasília - DF. *E-mail: moraisfelipe029@gmail.com ¿Universidade Federal de Alagoas (UFAL), Maceió - AL.

3Universidade de Brasília (UnB), Brasília - DF.

SUBMETIDO EM: 9/2020

ACEITO EM: 10/2020

PUBLICADO EM: 10/2020

REAS/EJCH | Vol.12(10) | e5208 | DOI: https://doi.org/10.25248/reas.e5208.2020

Página 1 de 6 


\section{RESUMEN}

Objetivo: Reportar un caso de un paciente con ictus isquémico, cirugía previa de revascularización miocárdica, comorbilidades cardiovasculares y endocrino-metabólicas asociadas a complicaciones por SARSCoV-2. Detalle del caso: Paciente de 75 años ingresado en un hospital de referencia de Brasilia/Distrito Federal en junio de 2020 por pérdida súbita del conocimiento, hemiparesia en dimidio derecho y afasia con desviación ocular conjugada durante 1 hora. Fue sometido a cirugía de revascularización miocárdica hace 3 años, tiene aún hipertensión arterial, enfermedad renal crónica estadio IV por la Colaboración Epidemiológica de Enfermedad Renal Crónica, hipotiroidismo, síndrome metabólico y síndrome de apnea obstructiva del sueño. Durante la hospitalización se realizó RT-PCR con detección de ARN del SARS-CoV-2 y TC de tórax que mostró opacidades con atenuación en vidrio deslustrado y broncopatía inflamatoria. Consideraciones finales: En presencia de coronavirus, el ictus isquémico se produce en los casos más graves de la enfermedad, debido al neurotropismo del virus y las complicaciones del paciente con comorbilidades cardiovasculares. La cirugía de revascularización miocárdica es un factor de peor pronóstico en el postoperatorio inmediato en estos pacientes con una alta tasa de mortalidad. Sin embargo, en el presente caso, el paciente con antecedentes de CABG tuvo un resultado clínico favorable.

Palabras clave: SARS-CoV-2, Accidente cerebrovascular, Revascularización cerebral.

\section{INTRODUÇÃO}

O SARS-CoV-2 é um betacoronavírus que causa a doença COVID-19. Segundo a Organização Mundial de Saúde (OMS), globalmente, em outubro de 2020, foram registrados 33.722 .075 casos confirmados, dos quais, 1.009.270 mortes. A doença geralmente se apresenta de forma leve tendo como sintomas mais característicos: febre, tosse seca e cansaço. Contudo, é possível ainda encontrar nos pacientes: dispneia, dor torácica, cefaleia, diarreia, anosmia, ageusia e erupções cutâneas.

Além disso, os casos graves que exigiam acompanhamento nas unidades de tratamento intensivo eram acompanhados por outras comorbidades como: hipertensão, doenças cardiovasculares, acidente vascular cerebral (AVC), doença renal crônica (DRC), diabetes e doenças pulmonares (WORLD HEALTH ORGANIZATION, 2020; WHITTAKER A, et al., 2020; MONTALVAN V, et al., 2020).

O vírus responsável pela pandemia atual, SARS-CoV-2, atua de forma similar ao SARS-CoV que surgiu em meados de 2002. O atual betacoronavírus se une ao receptor da enzima conversora de angiotensina 2 (ECA2) como acontecia com o seu antecessor. Este receptor é encontrado em diversas células do corpo humano, como células endoteliais, células musculares da túnica íntima e média das artérias musculares do cérebro, células gliais e neurônios. Este achado demonstra o potencial acometimento neurotrópico do SARSCoV-2, indicando a possível gravidade da doença (ZHOU Z, et al., 2020; WHITTAKER A, et al., 2020).

A denominação "coronavírus" surgiu devido à forma de coroa que o vírus encapsulado apresenta, quando observado à microscopia eletrônica. Esta coroa é constituída por glicoproteínas membranosas em formato espiculado. Outrossim, o betacoronavírus encerra em si mesmo um material genético constituído por uma fita simples de RNA, sendo considerado um dos maiores genomas do seu grupo.

Os coronavírus pertencem ao domínio Riboviria, reino Orthornavirae, filo Pisuviricota, classe Pisoniviricetes, ordem Nidovirales, família Coronaviridae e subfamília Orthocoronavirinae. Esta subfamília é dividida em quatro gêneros: Alphacoronavírus, Betacoronavírus, Gammacoronavírus e Deltacoronavírus. O Alphacoronavírus assenhorea as espécies HCoV-229E, HCoV-NL63 e Mi-BatCoV 1A. O Betacoronavírus abrange dentre outros os HCoV-OC43, HCoV-HKU1, MERS-CoV, SARS-CoV e SARS-CoV-2. O Gammacoronavírus possui como exemplares IBV, TCoV e BWCoV-SW1. O Deltacoronavírus a seu turno, apresenta, dentre outros: BuCoV HKU11, WiCoV HKU20 e ThCoV HKU12 (WOO PCY, et al., 2012; CARODARTAL FJ, 2020; BERGER JR, 2020).

Existem dezenas de coronavírus estudados, porém somente sete espécies, comprovadamente, infectam o ser humano: MERS-CoV, SARS-CoV, HCoV-HKU1, HCoV-OC43, HCoV-229E, HCoV-NL63 e, por fim, o 
atual SARS-CoV-2. Este, surgiu nos últimos meses, devido a exímia capacidade de mutação apresentada pelos coronavírus, permitindo inclusive a sua transmissão entre muitas espécies de mamíferos e aves (CAROD-ARTAL FJ, 2020).

Apesar de ser o mais comum, o sistema respiratório (SR) não é a única porta de entrada do COVID-19 nos seres humanos. Há muitos relatos na literatura científica que sugerem a invasão do vírus por meio do trato gastrointestinal. Esta teoria é corroborada pelo quadro clínico de muitos pacientes, associado não somente a sinais e sintomas respiratórios, mas também gastroenterológicos. Mesmo tendo o processo mecânico sido iniciado na mucosa nasofaríngea, ele continua pelo interior do SR e/ou gastrointestinal e, em resposta ao neurotropismo do SARS-CoV-2, pode adentrar inclusive no sistema nervoso central (SNC) do paciente.

O vírus reiteradamente manipula os sistemas linfático, vascular e até o sistema nervoso, notadamente o entérico para perfazer o SNC a seu favor. Desta forma, o betacoronavírus pode provocar AVC seguindo diversos mecanismos: acometimento vascular, com inflamação das suas paredes; hipercoagulabilidade; lesão miocárdica; liberação de placas ateroscleróticas do seu sítio de formação, bloqueando o fluxo sanguíneo a nível cerebral, levando a necrose tecidual entre outros (BOSTANCIJKLIJOGLU M, 2020; TREJO-GABRIELGALÁN JM, 2020).

Segundo Barrios-López JM, et al. (2020) e Trejo-Gabriel-Galán JM (2020), muitos acometimentos neurológicos foram analisados em pacientes com a COVID-19. Dentre eles, a categoria isquêmica do AVC foi identificada em 2-3\% dos pacientes hospitalizados na cidade de Wuhan, China. Constatou-se inclusive um aumento para $5-6 \%$ da incidência do AVC nos pacientes que expressaram a doença grave. A hipercoagulabilidade associada a níveis altos de D-dímero adstrito à eclosão da inflamação sistêmica confirmada por exames laboratoriais são fortes indícios de AVC nestes doentes.

$\mathrm{O} A V C$, pode ser dividido em isquêmico e hemorrágico. O primeiro é mais comum, representando aproximadamente $70 \%$ dos AVCs no mundo. O segundo, abrange hemorragia com foco intracerebral e hemorragia com foco subaracnoide. Com o desenvolvimento tecnológico da medicina, o diagnóstico do AVC teve um incremento na sua classificação. Exames de imagem mais sofisticados permitiram estratificar melhor - AVC com base em estudos mais aprofundados das lesões teciduais. Quando estas lesões não são permanentes, denomina-se ataque isquêmico transitório. Quando permanentes, diagnostica-se o AVC (CAMPBELL BCV, et al., 2019).

O presente trabalho teve como objetivo narrar um caso de paciente com AVC devido a complicações pelo betacoronavírus. O estudo apresentou ainda particularidades relevantes para o desdobramento da fisiopatologia do SARS-CoV-2 no enfermo, como: comorbidades cardiovasculares, endócrino-metabólicas, obesidade, histórico de tabagismo com carga tabágica de 30 maços/ano e senilidade. Além disso, paciente vinha com cirurgia de revascularização do miocárdio (CRVM) relativamente recente (há 3 anos), devido à doença arterial coronariana (DAC), o que justificou o estudo e publicação do caso na literatura científica.

\section{DETALHAMENTO DO CASO}

A.I.P., sexo masculino, 75 anos, foi admitido em hospital de referência em Brasília/DF em junho de 2020 com histórico de episódio de perda súbita de consciência seguida de hemiparesia em dimídio direito e afasia com desvio conjugado ocular por 1 hora. Realizada tomografia computadorizada (TC) de crânio sem contraste que afastou quadro de lesões isquêmicas ou hemorrágicas à admissão.

Paciente com história patológica pregressa de DAC com CRVM há 3 anos, hipertensão, DRC estágio IV pelo Chronic Kidney Disease Epidemiology Collaboration, hipotireoidismo, síndrome metabólica, síndrome da apneia obstrutiva do sono, hérnia de hiato e ex-tabagista, com carga tabágica de 30 maços/ano (UTIEL FJB, et al., 2020).

À admissão foi levantada hipótese diagnóstica de AVC isquêmico e complicações da DRC estágio IV com fibrilação atrial interrogada. Paciente referia uso contínuo de um antiagregante plaquetário, beta-bloqueador, diurético de alça, estatina, hormônio tireoidiano sintético e inibidor da xantina oxidase. 
Ao exame, encontrava-se em regular estado geral, sonolento, anictérico, acianótico, febril ao toque, hipocorado, desidratado e eupneico com suporte ventilatório de cateter nasal $5 \mathrm{~L} / \mathrm{min}$. Aparelho cardiovascular sem intercorrências com pressão arterial de $96 \times 72 \mathrm{mmHg}$ e frequência cardíaca de $84 \mathrm{bpm}$. SR com redução difusa do murmúrio vesicular fisiológico, sem ruídos adventícios. Abdome globoso, distendido, hipertimpânico, sem visceromegalias, indolor à palpação superficial e profunda, ruídos hidroaéreos presentes e sem sinais de irritação peritoneal. Pulsos pediosos e poplíteos bilaterais simétricos com leve edema e hemiplegia em dimídio direito. Apresentava afasia com comprometimento da área de Wernick e Broca.

Após uma semana de internação, paciente permaneceu sonolento, com afasia global e em uso de sonda nasoentérica instalada desde admissão. À nova TC de crânio sem contraste apresentou área hipoatenuante com acometimento do território da artéria cerebral média esquerda (ACME) que apresentava dificuldade na irrigação dos lobos frontal e parietal, além da ínsula, cápsula interna, núcleos caudado e lentiforme, estriado e porção do globo pálido.

Visualizado apagamento dos sulcos nos giros corticais. Presença de tênue compressão do ventrículo lateral e desvio da linha média contralateral em aproximadamente $4 \mathrm{~mm}$. Tronco cerebral esquerdo com hipoatenuação. Sem sinais de coleções extra-axiais ou focos de hemorragia intraparenquimatosa. Demais achados anátomo-fisiológicos à TC de crânio sem alterações. Com laudo conclusivo para AVC isquêmico agudo/subagudo em território da ACME, paciente ainda evoluiu com tosse produtiva, sono agitado e necessidade de incremento de suporte ventilatório.

Exames laboratoriais vinham com sódio $130,7 \mathrm{mmol} / \mathrm{L}$; potássio $6,3 \mathrm{mmol} / \mathrm{L}$; cloro $94 \mathrm{mmol} / \mathrm{L}$; glicemia sérica $202 \mathrm{mg} / \mathrm{dL}$; creatinina 2,26 mg/dL; ureia 137,1 mg/dL; amilase $187 \mathrm{U} / \mathrm{L}$; bilirrubinas totais 0,33 mg/dL; bilirrubina direta $0,04 \mathrm{mg} / \mathrm{dL}$; bilirrubina indireta $0,29 \mathrm{mg} / \mathrm{dL}$; magnésio $2,7 \mathrm{mg} / \mathrm{dL}$; proteínas totais $6,0 \mathrm{~g} / \mathrm{dL}$; albumina 4,0 g/dL; globulina 2,0 g/dL; TGO $47 \mathrm{U} / \mathrm{L}$; hemácias 5,81 milhões $/ \mu \mathrm{L}$; hemoglobina $17,1 \mathrm{~g} / \mathrm{dL}$; hematócrito $52,4 \%$; leucócitos $7.100 / \mu \mathrm{L}$; neutrófilos $82,3 \%$; eosinófilos $0 \%$; basófilos $0,9 \%$; monócitos $8,9 \%$; linfócitos $7,8 \%$ e plaquetas $200.000 / \mu \mathrm{L}$.

O que permite depreender a necessidade da correção dos distúrbios hidroeletrolítcos apresentados com terapia de reposição endovenosa de sódio devido à sua depleção, além de restrição de potássio na dieta e aumento da sua eliminação com diuréticos de alça administrados por via oral. No tocante à glicemia sérica elevada, e consoante à diabetes mellitus identificada previamente no paciente, é proposta terapia com análogo de insulina para resolução do quadro em tela.

Devido à piora do quadro clínico respiratório, em julho de 2020 foi realizada TC de tórax sem contraste que apresentou opacidades com atenuação em vidro fosco e linhas intralobulares de distribuição predominantemente periférica, bilaterais. Acometimento pulmonar aproximadamente de $60 \%$. Brônquios de paredes espessadas inferindo broncopatia inflamatória. Logo após, foi realizado o teste Reação em Cadeia da Polimerase com Transcrição Reversa (RT-PCR), sendo detectável para o RNA do SARS-COV-2, confirmando presença da infecção pelo coronavírus.

O paciente foi então submetido a tratamento para COVID-19, por 21 dias até melhora clínica. Os exames laboratoriais melhoraram paulatinamente com reversão da depleção de sódio e reajuste de potássio. Devido à insuficiência renal aguda com ureia e creatinina elevadas, paciente foi submetido à hemodiálise até restabelecimento da função renal. Houve leve melhora da função neurológica. Paciente evoluiu com estabilidade hemodinâmica, sem necessidade de drogas vasoativas e sem sinais de desconforto respiratório. Ao exame físico vinha lúcido e orientado em tempo e espaço, cooperativo a comandos, com diurese e evacuação fisiológicas preservadas. Apesar das comorbidades apresentadas pelo paciente, este teve boa resposta ao tratamento proposto e alta médica em agosto de 2020.

\section{DISCUSSÃO}

De acordo com Morassi M, et al. (2020), o AVC não é um achado comum em pacientes infectados pelo SARS-CoV-2. Contudo, quando diagnosticado, pode determinar prognóstico desfavorável. O paciente do presente estudo apresenta diversas comorbidades cardiovasculares e passado relativamente recente de CRVM o que, somados, definem um prognóstico negativo ao combate ao COVID-19. 
Yaghi S, et al. (2020), corroboram em seus estudos, a incidência do AVC isquêmico de 0,9\% num total de 3.556 pacientes. Ao passo que Barrios-López JM, et al. (2020) e Trejo-Gabriel-Galán JM (2020) determinam um maior aparecimento do AVC isquêmico como complicações do coronavírus. Segundo ambos os autores, 2,8\% dos enfermos diagnosticados com COVID-19 evoluíram com AVC e este número é ainda maior (5,7\%) nos doentes com comorbidades. Importante salientar a associação do AVC às elevadas taxas de D-dímero.

Apesar de relatos de AVC isquêmico em jovens acometidos pelo SARS-CoV-2, a maior prevalência ainda se encontra nos idosos. A média foi de 71 anos. A COVID-19 mostrou-se mais deletéria nos pacientes que apresentavam previamente hipertensão, dislipidemia, diabetes mellitus, asma, doenças cardiovasculares e doenças cerebrovasculares. A fisiopatologia da doença está correlacionada à inflamação e distúrbios da coagulação, o que justifica o AVC isquêmico (AVULA A, et al., 2020).

González-Pinto T, et al., (2020) também ratificam os prejuízos causados pelo SARS-CoV-2 no alargamento do tempo de protrombina, na inflamação sistêmica, na hipercoagulabilidade, na trombocitopenia e no risco aumentado para coagulação intravascular disseminada.

No caso relatado neste estudo, o paciente apresentava comorbidades cardiovasculares, endócrinometabólicas e neurológicas à admissão. O AVC isquêmico levou o enfermo à afasia de Wernick e Broca associadas à disartria e hemiparesia de dimídio direito. Após uma semana de internação, o doente evoluiu com dessaturação necessitando de suporte ventilatório. À TC de tórax sem contraste foram relatadas opacidades com padrão vidro fosco em aproximadamente $60 \%$ do parênquima pulmonar e broncopatia inflamatória importante.

Não foi possível confirmar anosmia ou ageusia devido ao quadro clínico do paciente. Todavia, como determinado pela literatura, os SR e SNC sofreram lesões importantes pela fisiopatologia do SARS-CoV-2. Os pacientes frequentemente referem cefaleia, tonturas, ageusia, hipogeusia, anosmia, hipoanosmia, e distúrbios de consciência, devido ao neurotropismo do COVID-19 (HESS DC, et al., 2020; MONTALVAN V, et al., 2020).

A fisiopatologia do SARS-CoV-2 transpassa o panorama das lesões miocárdicas, renais ou pulmonares, das arritmias cardíacas, dos distúrbios de coagulação e seus respectivos desdobramentos. Quando relacionados a procedimentos cirúrgicos, o coronavírus teve papel relevante no desfecho clínico dos pacientes. Em estudo realizado em Wuhan, China, 100\% dos doentes apresentaram pneumonia, 44\% precisaram de terapia intensiva, 32\% evoluíram com Síndrome do Desconforto Respiratório Agudo e $21 \%$ dos pacientes tiveram desfecho de óbito (PATEL V, et al., 2020).

O betacoronavírus é formado externamente por uma coroa glicoproteica espiculada. Estas espículas são cadeias de polipeptídeos que se unem aos receptores celulares no corpo humano. Esta união é intermediada pelas ECA2 localizadas nas superfícies dessas células. Os SARS-CoV-2 têm tamanho de 100-150 nanômetros e um RNA de fita simples positivo. Os receptores da ECA2 têm grande afinidade pelas espículas polipeptídicas dos coronavírus. Esses receptores são abundantes no SNC, mais especificamente, no sítio ventrolateral da formação reticular e no núcleo do trato solitário, ambos localizados na medula oblongata no tronco encefálico. Nesta região encontram-se aglomerados neuronais responsáveis pela função cardiovascular e respiratória (MONTALVAN V, et al., 2020; BERGER JR, 2020).

Yandrapalli S, et al. (2020) relataram um prognóstico desfavorável para paciente com COVID-19 e em pósoperatório de CRVM. No estudo, o paciente evoluiu com hipóxia e febre já no primeiro dia de pós-operatório (DPO). Em TC de tórax, veio o laudo de consolidação bilateral e, em estudo de RT-PCR detecção de SARSCoV-2. Tempos depois, o óbito pela pneumonia grave. Os autores também referem outros tipos de cirurgias com alta taxa de letalidade no pós-operatório. Todas com complicações cardiorrespiratórias e falência múltipla de órgãos.

Rescigno G, et al. (2020) demonstraram em estudo paciente obeso e etilista crônico com necessidade de CRVM por angina instável, troponina sem alterações e cateterismo cardíaco indicando DAC com estenose de artéria coronária principal esquerda. AVC prévio sem sequelas. Não obstante cirurgia bem-sucedida e ecocardiograma sem regurgitação tricúspide residual, paciente evoluiu com hipóxia, dispneia e febre. TC de tórax apresentou consolidação bilateral. Ecocardiograma indicou ventrículo esquerdo com funções 
adequadas, apesar de danos consideráveis em ventrículo direito. O padrão ventilatório agravou-se com óbito no nono DPO. Os autores demonstram crescente preocupação com os tratamentos cirúrgicos de urgência em pacientes com COVID-19, devido a desfechos clínicos frequentemente desfavoráveis, especialmente nas cirurgias cardiovasculares.

No atual estudo, observou-se que a CRVM foi realizada há 3 anos. Paciente ainda apresentava comorbidades cardiovasculares e endócrino-metabólicas e foi admitido em hospital com AVC isquêmico e posterior COVID-19 com laudo estabelecido por RT-PCR e TC de tórax. Contudo, o desfecho clínico do paciente foi favorável, com boa resposta ao tratamento proposto e alta médica em 28 de agosto de 2020.

Quando paciente dá entrada hospitalar com AVC isquêmico, o tratamento recomendado é a trombólise endovenosa ou, em casos mais específicos, trombectomia endovascular. O medicamento trombolítico tem por função dissolver o coágulo que está obstruindo o fluxo sanguíneo. O tempo ideal para administração do fármaco é de até 4,5 horas. Todavia, há relatos na literatura de benefícios em até 9 horas do AVC. A trombectomia, tanto quanto a trombólise, são mais eficazes, quanto mais rápido for iniciado o tratamento, sendo um dos fatores determinantes para bom prognóstico (CAMPBELL BCV, et al., 2019).

Pode-se concluir com o relato de caso versado que a fisiopatologia concernente às manifestações cardiorrespiratórias e neurológicas do COVID-19 ainda precisa ser estudada. Muitos estudos divulgados na literatura corroboram o neurotropismo do SARS-CoV-2 e suas complicações, principalmente nos pacientes com comorbidades. Todavia, ainda há muito a ser esclarecido sobre as alterações patológicas causadas nas células e tecidos dos pacientes acometidos pela doença.

\section{REFERÊNCIAS}

1. UTIEL FJB, et al. Comparación de las ecuaciones MDRD y de las antiguas ecuaciones CKD-EPI frente a las nuevas ecuaciones CKD-EPI en pacientes con trasplante renal cuando se emplea 51Cr-EDTA para medir el filtrado glomerular. Revista de la Sociedad Española de Nefrología. Nefrologia 2020;40(1):53-64.

2. WHITTAKER A, et al. Neurological Manifestations of COVID-19: A systematic review and current update. Acta Neurologica Scandinavica, 2020; Jul;142(1):14-22.

3. ZHOU Z, et at. Understanding the neurotropic characteristics of SARS-CoV-2: from neurological manisfestations of COVID19 to potential neurotropic mechanisms. Journal of Neurology, 2020; Aug;267(8):2179-2184.

4. WU Y, et al. Nervous system involvement after infection with COVID-19 and other coronaviruses. Brain, behavior, and immunity, 2020; Jul;87:18-22.

5. YAGHI S, et al. SARS-CoV-2 and Stroke in a New York Healthcare System. Stroke. 2020; Jul;51(7):2002-2011.

6. MORASSI M, et at. Stroke in patients with SARS-CoV-2 infection: case series. Journal of Neurology, 2020; Aug;267(8):21852192.

7. AVULA A, et al. COVID-19 presenting as stroke. Brain, behavior, and immunity, 2020; Jul;87:115-119.

8. WORLD HEALTH ORGANIZATION. Coronavirus Disease (COVID-19) Dashboard. 2020. Disponível em: https://covid19.who.int. Acesso em: 01 de outubro de 2020.

9. BOSTANCIJKLIJOGLU M. Temporal Correlation Between Neurological and Gastrointestinal Symptoms of SARS-CoV-2. Inflammatory Bowel Diseases, 2020; Jul 17;26(8):e89-e91.

10. MONTALVAN V, et al. Neurological manifestations of COVID-19 and other coronavirus infections: A systematic review. Clinical Neurology and Neurosurgery, 2020; Jul;194:105921.

11. BARRIOS-LÓPEZ JM, et al. Ischaemic stroke and SARS-CoV-2 infection: A causal or incidental association? Neurologia (Barcelona, Spain), 2020; Jun;35(5):295-302.

12. BERGER JR. COVID-19 and the nervous system. Journal of Neurovirology, 2020; Apr;26(2):143-148.

13. GONZÁLEZ-PINTO T, et al. Emergency room neurology in times of COVID-19: malignant ischaemic stroke and SARS-CoV2 infection. European Journal of Neurology, 2020; Apr 30;10.1111/ene.14286.

14. HESS DC, et al. COVID-19-Related Stroke. Translational Stroke Research, 2020; Jun;11(3):322-325.

15. TREJO-GABRIEL-GALÁN JM. Stroke as a complication and prognostic factor of COVID-19. Neurologia (Barcelona, Spain), 2020; Jun;35(5):318-322.

16. CAROD-ARTAL FJ. Neurological complications of coronavirus and COVID-19. Revista de Neurologia, 2020; May 1;70(9):311322.

17. WOO PCY, et al. Discovery of Seven Novel Mammalian and Avian Coronaviruses in the Genus Deltacoronavirus Supports Bat Coronaviruses as the Gene Source of Alphacoronavirus and Betacoronavirus and Avian Coronaviruses as the Gene Source of Gammacoronavirus and Deltacoronavirus. Journal of Virology, 2012; page 3995-4008.

18. YANDRAPALLI S, et al. Successful coronary artery bypass operation in a SARS-COV-2 infected patient with acute coronary syndrome. Journal of Cardiac Surgery, 2020; Jul 11;10.1111/jocs.14784.

19. RESCIGNO G, et al. A Case of Postoperative Covid-19 Infection After Cardiac Surgery: Lessons Learned. The Heart Surgery Forum, 2020; Apr 21;23(2):E231-E233.

20. PATEL V, et al. Cardiac Surgery During the Coronavirus Disease 2019 Pandemic: Perioperative Considerations and Triage Recommendations. Journal of the American Heart Association, 2020; Jul 7;9(13):e017042.

21. CAMPBELL BCV, et al. Ischaemic stroke. Nature Reviews Disease Primers, 2020; 5, Article number: 70. 